\title{
El viaje a Egipto. Primeros viajeros españoles y primeras miradas de la investigación española hacia las tierras del Nilo.
}

María J. López Grande.

Universidad Autónoma de Madrid

\section{Resumen}

Las escasas tierras de Nubia que al sur de Asuán emergen a orillas del lago Nasser evocan para mí, de manera muy especial, el grato recuerdo de Charo Lucas. Aquel pequeño espacio de Nubia conservado al sur de Egipto, el valle del Nilo en Egipto y Sudán, su enorme río y el viaje hasta aquellas tierras lejanas fueron muy significativos en un momento importante de la vida de la Profesora Lucas (Lucas Pellicer, 2002: 189-204). Para recordarla en este homenaje quiero aportar datos e ideas referidos a algunos de los viajeros que desde la antigüedad tardía y hasta finales del siglo XIX visitaron Egipto, recordando entre ellos a los que partieron hacia las tierras del Nilo desde nuestro país. Entendemos el "viaje a Egipto" como un hecho cultural en sí mismo, relacionado muchas veces con el inicio de la Egiptología y su consolidación como disciplina científica.

Palabras clave: Historiografía. Arqueología Egipcia. Egipto. Sudán. Antigüedades egipcias. Colecciones de arte faraónico. Libros de viajes.

\begin{abstract}
In recent years travel literature has witnesses a new interest and vigour by a wider range of scholars than ever before. Travel texts and documents have proved to be a prolific source of knowledge on lands, peoples and their cultures, but concerning Egypt they offer important details relating to archeological sites and antiquities, and give light on the tentative footsteps of Egyptology. The account of Spanish travellers to Egypt from late antiquity onwards, and the first academic researches done in Egypt on pharaonic subjects by Spanish scholars in XIX century, are well worth writing.
\end{abstract}

Key words: Egypt. Sudan. Travel Literature. Egyptian Archaeology. Egyptian antiquities. Ancient Egyptian Art Collections.

\section{1.- Egipto en la Memoria de Europa}

Recordemos que en Europa, a principios del siglo XIX, se acusó una actitud muy receptiva hacia el legado del antiguo Egipto. Esta tendencia contaba con una importante tradición pues desde la antigüedad estatuas, obeliscos y otros objetos de procedencia egipcia habían llegado a Europa y fascinado al hombre occidental que reconocía en ellos una peculiar estética y la fuerza y la sabiduría de la sociedad refinada y culta que en el pasado los había creado. Ahora bien, no en todos los periodos de nuestra historia la consideración hacia Egipto y lo egipcio había sido favorable (Assmann, 2003: 21-36).
Egipto había estado presente en la memoria de Occidente a través de algunas de las historias narradas en la Biblia, relatos que enfatizan las diferencias entre Egipto e Israel, entidades políticas que aparecen en el texto bíblico relacionadas entre sí por un entramado de vínculos políticos, comerciales e ideológicos en ocasiones amistosos, pero muchas veces conflictivos y siempre complejos. Israel, en la Biblia, encarna la verdad, mientras que Egipto simboliza la oscuridad y el error, representando todo aquello que Israel había sido capaz de superar con el Éxodo, sobre todo el paganismo o idolatría, pero también el pasado vivido por los israelitas en Egipto, etapa que "el pueblo elegido" se empeñaba en recha- 
zar para evitar que su recuerdo contaminara la tradición de Israel (Assmann, 2003: 19-20).

Moisés, el hebreo, es presentado en la Biblia como la personificación de la confrontación y el antagonismo entre Israel, la verdad, y Egipto, la falsedad. Moisés, el hebreo, el liberador del yugo egipcio fue, por tanto, para Occidente, el símbolo de la egiptofobia. Su figura bíblica mantuvo viva durante siglos en la tradición occidental una imagen de Egipto que era absolutamente antitética a los ideales occidentales, la imagen de Egipto como la tierra del despotismo, la hybris, la brujería, el culto a los animales y la idolatría (Assmann, 2003: 24).

Las fuentes clásicas, por el contrario, ofrecían una imagen muy distinta de Egipto, e incluso una versión muy diferente de la figura de Moisés. Pero hasta el Renacimiento Occidente no participó del conocimiento de los escritos clásicos en la misma medida en que lo había hecho de la Biblia. Por tanto, los relatos de Heródoto de Halicarnaso, Diodoro de Sicilia, Estrabón y Plutarco, entre otros, que nos hablan con admiración de la tierra del Nilo y del saber de los antiguos egipcios, no impactaron de manera decisiva en Occidente en los primeros catorce siglos de nuestra historia. Del mismo modo, la historia de Egipto escrita por Manetón de Sebenitos, sacerdote egipcio del siglo III a.C. para su monarca, Ptolomeo II Filadelfo (284-246 a.C.), y la versión que en ella se daba de Moisés, presentado como un sacerdote egipcio rebelde que se había erigido en líder de una colonia de leprosos, no pudo competir con la idea del Moisés hebreo del texto bíblico.

A pesar de las connotaciones negativas que Egipto y lo egipcio suscitaban en Occidente, viajar hasta las tierras del Nilo fue en muchos casos un destino deseado. Existían otras referencias bíblicas, como la huida a Egipto de la Sagrada Familia, narrada en el Nuevo Testamento (Mateo 2,23) y en otros textos apócrifos (Santos Otero, 1991: passim), que lo hicieron destino de peregrinaciones cristianas desde la antigüedad tardía. Cuando nació el Islam Egipto fue visitado por muchos peregrinos que desde Occidente, muchas veces desde Al-Andalus, viajaban a La Meca. Algunos de aquellos viajeros dejaron en sus escritos comentarios, casi siempre anecdóticos pues para ellos las antigüedades no tenían

1 El Moisés egipcio de Manetón personificaba la versión egipcia de un momento traumático de la historia de Egipto que, en opinión de J. Assmann (2003:17), hubo de estar referido originariamente al faraón Ajenatón (XVIII dinastía, 1352-1336 a.C.) y a su revolución especial interés, acerca de la grandiosidad de las ruinas o la peculiaridad de algunas obras arquitectónicas, como las pirámides, que tuvieron ocasión de ver a su paso por las tierras del Nilo (Gómez Espelosín; Pérez Largacha, 1997: 192).

El interés de Occidente por lo egipcio conoció un importante estímulo durante el Renacimiento, con el descubrimiento de supuestos "textos egipcios", como el tratado sobre jeroglíficos de Horápolo, descubierto en 1419 en la isla de Andros, en el Egeo, e impreso en traducción latina en 1505, y el Corpus Hermeticum, que fue llevado a Italia por un agente de Cosimo de Médicis en 1460, y traducido al latín en 1463 por Marsilio Ficino. Éste y otros escritores del Renacimiento como Francesco Colonna o Athanasius Kircher, reconstruyeron la filosofía hermética como si fuese la antigua teología y sabiduría del antiguo Egipto. Estos autores se sintieron capaces de completar la imagen clásica de Egipto que trasmitían los escritos griegos y latinos, casi unánime e inequívocamente egiptofílica, que contrastaba, de manera acusada, con la visión extremadamente egiptofóbica ofrecida por la Biblia.

\section{2.- Primeros viajeros a EgIPTO Y PRI- MEROS RELATOS DE VIAJES.}

Desde la antigüedad tardía y a lo largo de la Edad Media Egipto fue visitado por viajeros que desde Occidente peregrinaban a los Santos Lugares o a La Meca. De estos viajes quedaron crónicas escritas que nos permiten conocer la razón y la forma de su viaje (Cannuyer, 1991: 136-140), pero también aquello que al viajero llamaba la atención en su recorrido. Egipto sorprendía a los viajeros por su peculiar geografía, por algunos especímenes de su fauna, y por las abundantes y grandiosas ruinas de un pasado que se antojaba perdido, que aparecían esparcidas por el valle y los desiertos.

Entre estos primeros viajeros hemos de mencionar a la monja Egeria, virgen consagrada al dios de los cristianos en una comunidad religiosa gallega, que recorrió Tierra Santa, el norte de Egipto y la península del Sinaí en los últimos años del siglo IV (377-388) intentando identificar lugares y ciudades acerca de los cuales había leído en la Biblia. Sabemos que la dama Egeria visitó Alejandría, Menfis, las pirámides de Giza,

monoteísta, episodio que con el paso del tiempo y la pérdida en la memoria histórica de la figura de Ajenatón la tradición acabó asociando y finalmente fijando con los judíos. 
que observa a distancia e identifica como los graneros de José; tal vez Tanis (la tierra de Goshen) y el Mar Rojo, según afirma en su manuscrito Peregrinatio ad loca sancta, descubierto en Italia en 1883 (Gómez Espelosín; Pérez Largacha: 1997, 191).

Desde la Alta Edad Media contamos con relatos de viajeros cristianos, judíos y musulmanes que visitaron Egipto y dejaron descripciones o comentarios de sus viajes. Destacan, entre otros, el relato del cordobés Abu Obaid, en el siglo IX, y en el siglo XII el del judío Benjamín de Tudela y los de los musulmanes Mohamad Abu Abdala, el-Edrisi, ceutí; Abu Hamid al-Garnati, granadino, e Iben Yubair, valenciano. Éste último visitó Egipto y los Santos Lugares en su viaje de peregrinación a La Meca, realizado entre 1183 y 1185 (Gómez-Navarro: 2002: 99-103). A su regreso Iben Yubair escribió un libro titulado $A$ través del Oriente, en el que se describe el recorrido realizado y los lugares visitados, una obra con la que se inicia un nuevo género en la literatura árabe, la rihla o relación del viaje, que será muy utilizada por sucesivos viajeros, muchas veces para dejar establecidos los distintos caminos de peregrinación hacia la ciudad del profeta.

De los relatos de pluma cristiana de este periodo que informan sobre las tierras del Nilo, el mejor conocido es el titulado El viaje de Sir John Mandelville, caballero. Se trata de un libro de viajes que contiene enormes errores, pero que fue utilizado como manual por los viajeros occidentales durante los siglos XVI y XVII. Se discute en él sobre la escritura jeroglífica y se repite la interpretación, ya sugerida por otros autores, de las grandes pirámides como los graneros del José bíblico (Wortham, 1971: 6). En el siglo XIX se descubrió que John Mandelville nunca había existido y que el verdadero autor del relato había sido un hombre de Lieja (Bélgica), Jean d'Outremeuse, que nunca se había aventurado a salir de su país y que había escrito su relato, publicado en 1357 , basándose en obras de escritores más antiguos.

En los siglos XIII-XIV tenemos noticias de varios viajeros catalanes y alguno mallorquín que por diferentes motivos, y probablemente animados por acuerdos y tratados establecidos entre los reyes de Aragón y los sultanes de Egipto, viajaron hasta las tierras del Nilo. De este periodo cabe destacar al filósofo y escritor marroquín R. Llull (1235-1315) que a principios del siglo XIV visitó Alejandría, y a los catalanes Omberto de Fenollar y Jazpert de Camploch, enviados en 1366 por el rey Pedro IV el Ceremonioso (1336-1387) para negociar la libertad de varios comerciantes catalanes. En 1377 el mismo monarca encargó al caballero Bononato Zapera negociar en Egipto la libertad del rey de Armenia (Gómez-Navarro: 2002, 103-104).

Conviene también recordar a Pedro Tafur, hombre educado en el seno de la aristocracia urbana sevillana del siglo XV, enriquecida por el comercio y la industria. Tafur dejó una interesante crónica de los viajes que realizara entre 1436 y 1439 , relato que no fue escrito hasta 1454 ó 1455 y permaneció inédito hasta 1874; hoy es considerado uno de los mejores relatos de viajes de los últimos momentos de la Edad Media española. Las únicas motivaciones conocidas de Pedro Tafur para realizar su aventura fueron su gusto a viajar y su deseo de adquirir viajando mayores conocimientos. En sus viajes recorrió diversos lugares de Europa, Asia y África. A Egipto llegó procedente de Chipre; recorrió el Nilo visitando diversas ciudades y viajó hasta el monasterio de Santa Catalina, en la península del Sinaí. En su relato describe paisajes, gentes, animales, monumentos...; critica la pobreza de muchas ciudades y aldeas islámicas, y se muestra irritado ante la insalubridad de El Cairo.

Otro importante viajero fue Alhassan Iben Mohamed al-Wazzan al-Fassi al-Granati (14831554), conocido también como Juan León el Africano, nacido en Granada, en el seno de una familia noble. Visitó África del Norte, Egipto y parte de Asia. Fue hecho prisioneros por los cristianos en uno de sus viajes y llevado a Roma, donde en 1517 se convirtió al cristianismo con el nombre de Juan León de Médicis. Gracias a sus viajes realizó un importante trabajo de geografía titulado "Descripción de África" (1550) en el que se describen algunas ruinas de Egipto (GómezNavarro, 2002: 105-106). El Papa León $\mathrm{X}^{2}$ fue amigo personal de León el Africano que le había sido obsequiado como siervo. Y permitió la traducción de algunos escritos suyos a la lengua italiana. A la muerte del pontifice León el Africano abjuró del cristianismo y regresó a África y a la religión islámica. Murió en Túnez en 1554.

Con los relatos de estos y de otros viajeros Egipto había empezado, de manera lenta, a penetrar en Europa y a calar en el interés del hombre occidental. Pero el valle del Nilo era una tierra lejana y difícil en la que se conocían enfermedades endémicas y en la que habitaban una 
población islámica que resultaba hostil a la presencia europea (Guérin dalle Mese, 1991: 15-18). Así y todo, los sultanes mamelucos al frente de Egipto recibieron emisarios europeos, como el milanés don Pedro Mártir de Anglería, que fue enviado en 1501 como embajador de los Reyes Católicos para evitar que se obligara a los cristianos que vivían en Oriente a convertirse al Islam. Se conservan cartas de este viajero-embajador español que iluminan, sobre todo, aspectos de la diplomacia del momento (Galán, 1997: passim).

Algo más tarde, entre 1507 y 1512, el español Diego de Mérida, monje de la orden de los jerónimos, realizó un viaje por Oriente visitando Palestina, Chipre y Egipto del que se han conservado dos manuscritos originales que fueron dados a conocer por A. Rodríguez Moñino en 1946. Son apreciables los comentarios que ofrece de la ciudad de El Cairo, de sus iglesias cristianas, de sus mezquitas y de la corte del sultán mameluco. Pero sobre todo resulta muy interesante su descripción de la meseta de Giza y de las grandes pirámides, a las que el monje llama "pirámides del faraón, septem mirabilibus mundi de quibus narrat philosophus..." (Cannuyer, 1998: 11) situadas entonces "a tres leguas de El Cairo". Realiza esta excursión saliendo por mañana muy temprano, a la primera llamada a la oración, "dos horas antes del día..." acompañado de tres mamelucos, uno de ellos de Sevilla, que ejercen de guías, y de otros cristianos que como él van de excursión; unos van a caballo, otros en asnos, y todos cruzan el Nilo en barca. Diego de Mérida dice haber visto dieciséis pirámides, monumentos a los que a lo largo de su relato también llama "montañas del faraón". ${ }^{4}$ De ellas dice que son "obras admirables tanto al interior como al exterior" ofreciendo detalles que permiten saber que estuvo en la "cámara del rey" de la pirámide de Keops. De acuerdo a los datos ofrecidos los viajeros se movieron y contemplaron un amplio territorio de la necrópolis menfita, probablemente el correspondiente a Giza, Saqqara, Abusir y Dashur, aunque es muy probable que muchas de las pirámides fueran vistas en la distancia, sin que lleragan a acercarse a los monumentos. ${ }^{5}$

Después de esta visita a las pirámides Diego de Mérida volvió a El Cairo desde donde prosiguió su viaje hacia Sinai. Visitó después el monasterio de San Marcos en Wadi Natrún, en el desierto Líbico, y desde allí se desplazó hasta Alejandría donde embarcó con destino a Rodas.

Egipto mantuvo desde el inicio del dominio otomano (1517) tratados que permitían viajar y comerciar a franceses y catalanes con la nueva provincia del imperio. A los viajeros se les daba protección religiosa, no serían acosados por no practicar el Islam, y se les garantizaba una relativa seguridad para sus viajes. A lo largo de los siglos XVI y XVII los viajes a Egipto desde Occidente se hacen relativamente frecuentes y Europa conoce bastantes relatos de viajeros muchos de ellos ingleses como Lawrence Aldersey, John Evesham o Georges Sandys, que describen las ruinas de Alejandría, las pirámides de Giza y las ruinas de Menfis (Wortham, 1971: 12-17). Algunos se aventuran con antorchas en el interior de pirámides y de otras tumbas. Suelen ser viajeros de cuidada educación, con conocimiento de lenguas clásicas e incluso de árabe, que remontan el Nilo llegando algunos de ellos hasta Tebas, como los jesuitas franceses Protias y François, que midieron y estudiaron muchas ruinas aunque no llegaron a identificarlas (Romer, 1985: 39).

Pocas noticias tenemos de españoles que en aquellas fechas viajaran a Egipto. Thomas Pettigrew, prestigioso médico inglés y el más célebre "abridor de momias" (Brier, 1996: 185186), en su libro History of the Egyptian Mummies, publicado en Londres en 1834, nos explica cómo el comercio de momias entre Egipto y Europa, que las utilizaba con fines terapéuticos, llegó a ser un negocio tan próspero que llevó a que los cadáveres momificados procedentes de tumbas antiguas escasearan. Comenzaron entonces prácticas irregulares para mantener una oferta capaz de satisfacer la demanda. Según Pettigrew Guy de la Fontaine, natural de Navarra, llevó a cabo en 1564 una investigación del mercado de momias en Alejandría, ciudad en la que más asentado estaba aquel negocio. Cuando examinó los almacenes en los que se conservaban las momias que iban a ser enviadas a Europa comprobó que se estaban momificando cadáveres recientes, a menudo de criminales que habían sido ejecutados. Para que aquellos muertos recientes adquiriesen el aspecto de momias anti-

vistas por Diego de Mérida y sus acompañantes fueron las de Giza, con las pirámides de Keops más sus tres pirámides satélites, Kefren, Micerinos y sus tres satélites (9 pirámides); más Saqqara, con las pirámides de Djeser, Unas y Sahure (3), más Abusir, con las pirámides de Neferirkare y Niuserre, y Dashur, con las pirámides "romboidal" y "roja" de Snefru.
34.175 metros (Doursher, 1945:210)

4 La equiparación de las pirámides con montañas también se conoce en la correspondencia de Pedro Martir de Anglería y puede tener su origen en una cita del Corán $(18,47)$ en la que se dice que Dios creó las pirámides al mismo tiempo que las montañas (Cannuyer, 1998: 13).

5 Cannuyer (1994: 14) sugiere que las dieciséis pirámides 
guas se les trataba con betún y se le ponía al sol para que se resecaran.

Sabemos de un franciscano español, Antonio del Castillo, nacido en Málaga, que realizó un viaje de peregrinación a Tierra Santa a mediados del siglo XVII. En 1654 publicó la primera edición del relato de su viaje que fue reeditado en numerosas ocasiones. Dedica en él páginas a Alejandría, el Nilo y El Cairo y describe los monumentos más llamativos, como las pirámides de las que comenta:

"Tres leguas distante del Cayro fuimos a ver las pirámides (...) hay tres grañidísimas y otras mas pequeñas. La mayor de todas es en la que está el sepulcro del Faraón. Su altura es indecible. Tiene 2600 passos de circuito y 1552 passos de alto. De diez y seis personas que fuimos a ver esta maravilla, solo las tres subimos a lo alto, que fue otro religioso y yo y un turco. Los demás subian hasta que sus fuerças y valor alcaçavan, y alli se quedavan. Son todas estas pirámides hechas de piedra de notable grandeza, porque avrá algunas que pesarán mas de ciento y cincuenta arrobas; y la maravilla grande es que no aviendo en todo el Egipto piedra alguna, de suerte que si buscasse en todo él una del tamaño de una nuez, no fuera posible hallarla. No se sabe de dónde o cómo traxeron piedras de tal tamaño y tantas; y cómo las subieron a tan encumbrada altura es lo que admira y espanta”. (GómezNavarro, 2002: 111-112).

\section{3.- VIAJEROS ILUSTRADOS Y GRANDES LIBROS DE VIAJES}

A lo largo del siglo XVIII varios exploradores europeos remontaron el Nilo hasta el Alto Egipto. Uno de ellos fue el jesuita francés Claude Sicard (1677-1726) que en 1707 identificó por primera vez la antigua Tebas (Luxor) y sus principales centros religiosos. Realizó un mapa completo y científico desde el Mediterráneo hasta Asuán, en el que localizó los monumentos más significativos (Romer, 1985: 39-40). También el reverendo inglés Richard Pococke (1704-1765), a quien debemos la primera descripción moderna del Valle de los Reyes (Romer, 1985: 40-41) acompañada de un plano detallado del mismo, aparecidos en su libro Observations on Egypt, publicado en Londres en 1743 (Reeves; Wilkinson, 1999: 52-53); el escocés James Bruce siguió los pasos de Pococke, adentrándose en el Valle de los Reyes y visitando algunas tumbas reales que en su obra Travels to Discover the Source of the Nile, aparecida en Ediburgo en 1790, son descritas como "sepulcros magníficos y estupendos". Otro viajero inglés, Williams Georges Browne (1768-1813), visitó Egipto en 1792. Su obra, Travels in Africa, Egypt and Syria, ofrece los escasos datos que conocemos sobre el interés de los árabes por el Valle de los Reyes. Browne comenta que en los treinta años previos a su visita el hijo de un jeque había explorado aquel territorio, en busca de tesoros.

Hemos de recordar también, en esta rápida mirada hacia los viajeros ilustrados que visitaron Egipto y sus grandes obras, al danés y capitán de la marina Frederick Ludwig Norden (1708-1742) que llevó a cabo largas exploraciones, adentrándose en las tierras de Nubia. Sus viajes quedaron plasmados en su obra Travels, bellamente ilustrada, publicada por vez primera en 1751 , dando a conocer en Europa los monumentos faraónicos.

La sociedad europea recibía con agrado los relatos de los protagonistas de aquellas exploraciones, publicados en grandes libros ilustrados que recogían toda la experiencia y conocimientos derivados de su aventura. Aquellas obras eran ventanas abiertas hacia los fabulosos lugares visitados; extraordinarias formas de difusión que imbuyeron en muchos de sus lectores el ansia de viajar y de conocer de primera mano las maravillas que en los libros estaban descritas. La publicación de aquellos libros suponía, en casi todos los casos, un beneficio y ganancia para el autor y para el editor. Eran obras de gran formato y a menudo de varios volúmenes. Las ilustraciones las realizaban los propios autores, o artistas que para ese fin emprendían con ellos el anhelado viaje.

En los últimos años del siglo XVIII (desde junio de 1798 a septiembre de 1801) tuvo lugar la expedición napoleónica a Egipto, que condujo al primer estudio sistemático de sus monumentos y a la publicación de una obra formidable, la Description de $l$ Egypte, una extraordinaria enciclopedia sobre el país egipcio, sus gentes, su geografía, su flora, su fauna, su geología y todos los monumento antiguos y medievales visibles en aquella época, que fueron convenientemente medidos y dibujados por una cohorte de sabios que Bonaparte llevó consigo y con sus soldados a las orillas del Nilo (López Grande, 2002: 6870). Los estudiosos iban al ritmo de las tropas y trabajaban aprovechando los descansos entre las contiendas y las distintas escaramuzas. Cuando el ejército volvía a emprender la marcha se desplegaban exploradores para recuperar a los sabios dispersos por la región y éstos tenían que incorporarse a las columnas militares hubieran o no terminado el trabajo emprendido. La expedición reunió unas tres mil ilustraciones que fueron la base de los diversos volúmenes de la Description de lEgypte,que costó veinte años de trabajo editorial y una suma impresionante a la tesorería francesa, primero bajo Napoleón y más tarde bajo la dinastía restaurada de los Borbones. 
La expedición francesa fue una fuente directa de la llegada a Europa de antigüedades egipcias desde su procedencia original en las tierras del Nilo. Muchos objetos antiguos egipcios llegaron a Francia, pero los quince monumentos más importantes que los franceses habían consignado como propiedad científica de la expedición fueron desviados a Londres en virtud del artículo XVI del Tratado de Alejandría (López Grande, 2001: 279); entre ellos la Piedra de Rosetta (Clayton, 1984: 26), ${ }^{6}$ monumento que iba a ser una pieza inestimable en el desciframiento de la escritura jeroglífica egipcia, labor que emprendida por diversos sabios fue brillantemente culminada en 1822 por Jean François Champollion (1790-1832).

Aquellos acontecimientos, el conocimiento directo de objetos egipcios y la difusión de los grandes libros de viajes hicieron que Europa se fascinara completamente con Egipto y con lo egipcio. La consecuencia inmediata fue que desde momentos muy tempranos del siglo XIX muchos europeos sintieron el deseo, y casi la necesidad, de viajar y conocer de primera mano los lugares y tesoros que existían en Egipto.

España no fue ajena a la fascinación por Egipto y desde los primeros años del siglo XIX sabemos de viajeros que recorren Oriente Próximo y Egipto. Como primer viajero español hacia dicho destino hay que recordar al barcelonés Domingo Badía i Leblich, nacido en 1767, más conocido como Alí Bey el-Abbasy, uno de los primeros viajeros occidentales del siglo XIX que recorrió el mundo árabe-musulmán haciéndose pasar por un rico príncipe abbasí de Damasco. Visitó Egipto además de Marruecos, Trípoli, Grecia, Chipre, La Meca, Palestina, Siria y Turquía. Sus intereses eran de carácter político y científico; era un hombre ilustrado, seguidor de la Revolución Francesa, informador de Manuel de Godoy y partidario en España de José Bonaparte, por lo que, a la caída de éste, hubo de exiliarse a Francia donde en 1814 publicó el relato de sus viajes (Badía i Leblich: ed. 1996: passim).

Abundan en la obra de Badía los detalles políticos de su momento y los datos científicos, pero además ofrece interesantes descripciones de antigüedades de Alejandría y de la zona de Giza que el autor visitó desde El Cairo para poder contemplar las grandes pirámides y la esfinge. A pesar de su interés en aquellos antiguos monumentos Badía relata que no pudo llegar hasta ellos pues en sus inmediaciones habitaban forajidos peligrosos, pero los contempló ayudándose de instrumentos como el "telescopio acromático" y el "anteojo militar Dollond" que en 1806, fecha de su visita a Egipto, eran sin duda sofisticados (López Grande: 2004, 80-81). Ofrece la descripción de las grandes pirámides a las que considera "enormes colosos levantados por la mano del hombre" y anota sus reflexiones sobre sus dimensiones y sobre la cronología admitida en su momento para aquellas grandes construcciones, demostrando en sus comentarios conocer bien el relato de Heródoto.

\section{4.- LA PODEROSA ATRACCIÓN DEL VALLE DE LOS REYES}

Desde los primeros años del siglo XIX hay viajeros europeos que fijan su atención en la exploración del Valle de los Reyes, como el inglés James Burton (1788-1862) y el paduano Giovanni Battista Belzoni (1778-1823). Conocen sin duda el trabajo de los exploradores que les han precedido, y muchos de ellos la publicación de la Description de lÉgypte, aparecida por entregas entre 1809 y 1828 , que incluye el mapa realizado por los ingenieros Prosper Jollois y Eduard de Villiers du Terage, el primer estudio exacto del yacimiento que supera en detalles y precisión los planos y mapas del lugar realizados previamente.

Las nuevas exploraciones de la necrópolis real conllevan el descubrimiento de nuevas tumbas de los antiguos reyes de Egipto, todas ellas saqueadas en época antigua pero algunas de gran belleza como las de Seti I (KV 17) o la de Ay (WV 23), halladas por Belzoni. Son hallazgos que en aquellos momentos resultaban difíciles de valorar dado que aún no se habían descifrado los jeroglíficos y era imposible adscribir las tumbas a reyes concretos a pesar de la presencia de inscripciones. Junto a estos descubrimientos los europeos que recorren el Valle de los Reyes y todo el territorio egipcio se interesan por las piezas antiguas y su traslado a Europa, destinadas muchas veces a las nacientes colecciones de los grandes museos en donde eran muy admiradas, aunque no suficientemente valoradas (López Grande: 2001, 277-294).

Egipto recibía cada vez con mayor frecuencia viajeros occidentales, muchos de ellos estudiosos cuya labor no cesaba, iniciando con su trabajo la andadura de la Egiptología. Entre ellos es preciso destacar al joven inglés Sir John Gardner

6 Museo Británico, Londres, EA-24; 
Wilkinson (1797-1875), formado en Oxford, que en 1824 se instaló en Gurna, una de las aldeas de la orilla occidental de Luxor, levantada en el desierto. Wilkinson se interesó por la cultura material de los antiguos egipcios y escribió una obra fundamental que todavía hoy se reedita: Manners and Customs of the ancient Egyptians. Utilizando el método de J.F. Champollion, dado a conocer en 1822, Wilkinson fue capaz de leer los nombres de los reyes en las inscripciones jeroglíficas y a partir de 1826 estableció una primera lista cronológica de los faraones del Reino Nuevo basándose en la documentación que proporcionaba el Valle de los Reyes y en otras inscripciones. Realizó el primer inventario y clasificación de las tumbas reales de la necrópolis real y en 1827 inscribió el número por él adjudicado a cada tumba a la entrada de la misma, estableciendo la nomenclatura KV (King's Valley) para las tumbas del Valle de los Reyes, y WV (Western Valley) para las tumbas reales del Valle Occidental, actualmente vigente. Hasta 1830 J.G. Wilkinson copió inscripciones y escenas de las tumbas reales, trabajo reunido en un importante número de volúmenes que desde 1834 se conserva en el Museo Británico (Londres), institución con la que Sir J.G. Wilkinson siempre colaboró de muy buena gana. En 1835 publicó en Londres Topography of Thebes, and General View of Egypt, una obra muy bien documentada para su tiempo que fue muy utilizada por viajeros que visitaban el valle del Nilo. Algo más tarde publicó una guía de viaje destinada a aquellos interesados en conocer Egipto, obra que también fue útil a los viajeros: A Handbook for Travellers in Egypt. London, 1847.

El propio J.F. Champollion visitó Egipto entre 1828 y 1829 liderando una expedición francotoscana de la que formaban parte el pisano Ippolito Rossellini (1800-1843) y el dibujante Nestor l'Hote. Para Champollion visitar Egipto y conocer in situ las inscripciones que estudiaba era fundamental para ratificar sus investigaciones. Recorrió todo el valle egipcio del Nilo y se detuvo un tiempo en Luxor, la antigua Tebas, para conocer de primera mano las ruinas de los grandes templos de la orilla oriental y las tumbas de los faraones ubicadas en el desierto occidental, que le interesaron de manera muy especial.

\section{5.- EgIPTO EN LA ESTAMPA ORIENTAL.}

La belleza de aquellos lugares quedaba bien expresada en las ilustraciones de los grandes libros que se iban publicando en Europa. Para algunos artistas la idea de captar aquellas imágenes en dibujo o acuarela fue el motivo fundamental para realizar el viaje a Egipto, pues la fas- cinación de la estampa oriental así lo justificaba. Este fue el caso del afamado artista escocés David Roberts (1796-1864) que recorrió Egipto entre 1838 y 1839, visitando además Sinaí, Palestina y Syria y realizó una importante obra pictórica durante su estancia, que pronto fue conocida y valorada en Europa (López Grande: 2004b: 14-16). La inquietud artística llevó también a Egipto al inglés Robert Hay (1799-1863) y al equipo que le acompañaba (Dawson, Uphill: 1995, 194), autores de reproducciones de escenas y textos jeroglíficos de algunas tumbas reales y de otros monumentos faraónicos.

Las obras de estos artistas son relatos magníficos, claras expresiones de lo que en aquellos días la habilidad en el dibujo, el apunte o la acuarela -que tan dignamente sustituían a la fotografíapodía captar de la exótica realidad geográfica y social de Egipto, una pintoresca actualidad que se superponía a un pasado remoto y magnífico, cuyo legado yacía escondido entre las arenas del desierto y las brumas del olvido; un tiempo lejano y fabuloso que el interés, la curiosidad y la fascinación de occidente comenzaban a descubrir y conocer.

\section{6.- VIAJEROS Y ESTUDIOSOS EUROPEOS Y GOBERNANTES EGIPCIOS}

En este clima orientó desde España su aventura hacia Egipto don Antonio de Orleáns, duque de Montpensier, afincado en Sevilla. Era el hijo menor del rey de Francia Luis Felipe de Orleans y estaba casado con la infanta María Luisa, matrimonio del que nacería María de las Mercedes (1860-1878), primera esposa de Alfonso XII (1857-1885).

Conocemos bien el viaje que don Antonio de Orleáns realizó en 1845 a las tierras del Nilo gracias al relato que del mismo escribió su secretario Antonio Latour, publicado en 1849. Aquel viaje coincidió en el tiempo con la magnífica expedición prusiana dirigida por el egiptólogo, lingüista y Museógrafo Richard Carl Lepsius (1810-1884), que contaba con la aprobación y el apoyo de Federico Guillermo III de Prusia (17701840), que consiguió para las colecciones de sus museos más de quince mil objetos antiguos que fueron llevados a Berlín, regalados oficialmente por Mohamed Alí (1805-1848), bajá de Egipto.

La visita a Egipto de don Antonio de Orleáns era de carácter oficial, en calidad de embajador de Francia. Su viaje no tenía la pretensión de ser una expedición científica, pero iba acompañado de dibujantes, pintores y de los primeros fotógrafos, lo que permitió que a la vuelta a Europa pudieran editarse espléndidos grabados y buenas 
fotografías. Además de los encuentros oficiales con Mohamed Ali en El Cairo, bien documentados por Antonio Latour, su libro narra la visita a las grandes pirámides de Giza y otras excursiones a lugares de interés arqueológico. La embarcación en la que viajaban remontó el Nilo hasta Asuán, y de regreso visitaron las ruinas de los grandes templos faraónicos de Karnak y Luxor y las tumbas de los antiguos monarcas, en el ya por entonces bastante explorado Valle de los Reyes, en desierto Occidental. Hasta la necrópolis real don Antonio de Orleáns se desplazó a caballo, antes del amanecer. Antonio Latour ofrece en su libro un detallado relato de aquella visita:

"Echamos pie á tierra en una especie de encrucijada desierta, en la cual se hallan de distancia en distancia unas puertas practicadas en la roca: de estas hay diez y seis y todas dan entrada á otras tantas tumbas, verdaderos palacios subterráneos, donde se baja con hachas encendidas por escaleras casi arruinadas, y donde sin cesar el pié del visitante se posa sobre restos de toda clase. A estas escaleras sucede un profundo corredor al cual dan, a derecha e izquierda, pequeñas salas de forma rectangular y que va á terminar a una larga galería donde solía descansar en un sarcófago, la momia del soberano. S.A.R. visitó los más notables de estos monumentos, los Rhamses-Meyamun, de Amenofis y de Thutmosis y descendió hasta el fondo, parándose á cada paso para reconocer los nichos de estas lúgubres y extrañas mansiones. Las murallas, cubiertas por todas partes de esculturas y pinturas, algunas veces muy finas, revelan en sus costumbres y maneras más familiares la primitiva civilización del Egipto".

A medida que se sucedían los hallazgos arqueológicos, las expediciones científicas y la investigación en los museos europeos que adquirían las grandes piezas faraónicas traídas por exploradores y tratantes de arte a Europa, la idea y la ilusión de viajar a Egipto se fue extendiendo por amplios sectores de la sociedad europea y acercándose progresivamente a las posibilidades de un mayor número de personas. Según avanzaba el siglo XIX los transportes cambiaban, el vapor conseguía mayor velocidad en los barcos y se impulsaba el desarrollo de los ferrocarriles (Gómez-Navarro, 2002: 98-123). Así, la posibilidad de viajar alcanzó a la alta burguesía que se sumó encantada a estas experiencias. Muchos de aquellos que realizaban el viaje a Egipto iban anunciando a medida que su aventura avanzaba noticias, relatos e imágenes de los territorios, gentes y lugares que visitaban mediante las cartas que escribían a sus amigos y familiares en Europa, documentos que constituyen una fuente documental de gran importancia que ayuda a conocer cuál era la percepción particular de aquellos viajeros -muchas veces mujeres- de la realidad que encontraban en aquellas tierras lejanas a las que habían anhelado viajar (Benson, 1917: passim; Nightingale, 1998: passim).

Egipto a mediados del siglo XIX era un país oriental que estaba cambiando. En 1854 llegaba al poder el Jedive Said (1854-63) amigo de del ingeniero y diplomático francés Ferdinand de Lesseps (1805-1894), promotor de la construcción del canal de Suez, importante empresa concluida e inaugurada en 1869. El canal de Suez abría un nuevo camino marítimo hacia La India y el lejano Oriente que pasaba necesariamente por Egipto, circunstancia que el jedive quiso aprovechar impulsando la construcción de ferrocarriles, inaugurándose la línea que unía Alejandría con Suez en 1859.

\section{7.- EXTRANJEROS, ANTIGÜEDADES Y AUTORIDADES EGIPCIAS}

También cambiaba en Egipto el valor otorgado a las antigüedades, y empezaban a surgir, gracias al impulso de intelectuales europeos, franceses sobre todo, las primeras instituciones que se ocupaban de su custodia y protección, pues eran muy graves los saqueos que el patrimonio egipcio estaba sufriendo. La salida de Egipto del gran número de piezas faraónicas regaladas a R.C. Lepsiups para los museos prusianos había provocado comentarios muy desfavorables y habían llevado la atención hacia las antigüedades, muy descuidadas por el gobierno egipcio, y hacia el tráfico de las mismas. La abundancia en Egipto de restos arqueológicos visibles, que incluían enormes conjuntos arquitectónicos y grandes esculturas, provocaba en los habitantes del país y en sus gobernantes una gran indiferencia. Aquellas ruinas sólo entrañaban para los egipcios el valor práctico que de ellas pudiera obtenerse por lo que en muchos casos los lugares arqueológicos eran ricas canteras de las que se obtenían sin demasiado esfuerzo materiales para la construcción de nuevos edificios, o incluso materia prima para la fabricación de cal o salitre.

Sabemos que bajo el mandato de Mohamad Alí se decidió la construcción de una serie de presas en la zona del Delta, destinadas a repartir las aguas de los brazos del Nilo de Rosetta y Damieta. Para llevar a cabo la obra Mohamed Alí planteó al director de los trabajos, el francés Louis Maurice Adolphe Linant de Bellefonds (17991883), conocido también como Linant Bey o Linant Pashá (Kurz; Linant de Bellefonds, 1998: 61-70), la idea de demoler las pirámides de Giza 
para utilizar sus bloques de piedra para las presas. Una comisión de Obras Públicas llegó incluso a la meseta de Giza para estudiar la viabilidad del proyecto. Linant Bey, reputado geógrafo, explorador, artista e ingeniero, era contrario a esta idea y consiguió disuadir a Mohamed Alí haciéndole ver lo costoso que sería el desmantelamiento de los grandes monumentos. Final y felizmente, las presas fueron construidas con materiales procedentes de canteras naturales (Gil Palenque, 2001: 342-343).

La indiferencia mostrada por los gobernantes egipcios hacia las antigüedades faraónicas estaba ocasionando la pérdida y dispersión del legado del antiguo egipto. La situación llegó a ser tan alarmante que hubo quejas emitidas desde Europa que hicieron variar la actitud de las autoridades egipcias hacia su patrimonio arqueológico. Mohamad Ali y sus descendientes estuvieroninteresados en mantener buenas relaciones con Europa, especialmente con Francia que en aquellos años proporcionaba a Egipto la infraestructura y el dinero necesarios para llevar a cabo la modernización del país. Los gobernantes egipcios apoyaron por tanto a los científicos europeos, especialmente a los franceses. En 1835 se dieron los primeros pasos para la salvaguarda del patrimonio arqueológico de Egipto. Mohamad Ali, sin duda en aras de abordar de manera diplomática las quejas levantadas en Europa sobre la indefensión del legado faraónico, proclamó el 15 de agosto de aquel año un edito que contemplaba medidas para evitar la salida incontrolada de antigüedades hacia Europa (Reid, 2002: 56-57). En el decreto se especificaba que antigüedades susceptibles de ser sacadas de forma ilegal del país habían de ser enviadas, para evitar su tráfico, al señor Rifaa al-Tahtawi (1801-1870), director de la Escuela de Lenguas ubicada en Ezbekeiya, un barrio situado en las inmediaciones del viejo Cairo, a orillas del lago que le daba nombre. El decreto establecía la construcción de un nuevo edificio junto a la Escuela de Lenguas destinado a albergar y exhibir las antigüedades que fueran reunidas, para que pudieran admirarlas los viajeros que visitaran el país, sin sugerirse otra posible audiencia interesada. Como supervisor de este planeado museo, en el que podemos encontrar el embrión del futuro Museo Egipcio de El Cairo, se nombró a Yusuf Diya Efendi, y se estableció que entre las funciones del director estaría la inspección anual de los lugares arqueológicos del Alto Egipto, visita en la que además de supervisar los lugares arqueológicos se recogerían antigüedades que irían ampliando la colección.

Con estos primeros pasos se iniciaron las trayectorias del Servicio de Antigüedades y del
Museo Egipcio de El Cario. Las primeras medidas de protección y control de las antigüedades estaban dictadas, eran significativas pero resultaban insuficientes para salvaguardar el legado faraónico. Las dificultades que conllevaba el control de los lugares y objetos arqueológicos en un país de patrimonio tan rico como Egipto eran enormes, entre otras muchas la amplia dispersión de los yacimientos, la localización de muchos de ellos en zonas despobladas o escasamente habitadas; la presencia, cada vez mayor de extranjeros interesados en llevarse con ellos al final de sus viajes objetos faraónicos, la indiferencia de los egipcios y, sobre todo, la consideración, de acuerdo a la legislación que estuvo vigente hasta 1857 , de que las antigüedades eran propiedad del jedive. El mismo Mohamad Alí, poco después de proclamar el decreto mencionado, ordenó la construcción de dieciocho fábricas de salitre; para la construcción de una de ellas se dinamitó el noveno pilono de templo de Karnak en Luxor.

Unos años más tarde, en 1848-49, se ordenó a Linant de Bellefonds la realización de un inventario de yacimientos de época faraónica, y la recogida de piezas para aumentar la colección de antigüedades reunida en Ezbezkeiya. El edificio destinando a museo no se había llegado a construir y las piezas reunidas seguían almacenadas en la Escuela de Lenguas, un lugar poco apropiado, con escasa vigilancia y mucha humedad ya que el barrio de Ezbekeya era alcanzado cada año por la crecida del Nilo. Según Gastón Maspero (18461916) la colección fue trasladada en 1851, bajo el mandato de Abbas Hilmi (1848-1854) y a petición del mismo, a la Ciudadela de Saladino, situada también en El Cairo (Reid, 2002: 58), donde las antigüedades ocupaban una sala y estaban mejor vigiladas que en su anterior emplazamiento. Otra fuente señala sin embargo que Abbas Hilmi desplazó en 1849 la colección a otro inmueble cairota ubicado en Nasriyya, en la zona de Sayyda Zaynab. En cualquier caso, la Ciudadela de Saladino o Nasriyya fueron destinos breves para el emplazamiento de la colección, pues poco después de su salida de Ezbezkeiya una parte de la misma fue trasladada a la Escuela de Ingenieros, en Bulaq, en la periferia de El Cairo de entonces, y el resto salió del país con destino a Estambul (Turquía), regalado por Abbas Hilmi al sultán otomano Abdulazziz. Unos años más tarde, en 1855, el jedive Said (1854-1863) regaló al archiduque Maximiliano de Austria (1811-1865) el resto de la colección, que hoy se exhibe en el Kunsthistorischen Museum de Viena.

En 1850 François Auguste Ferdinand Mariette (1821-1881), había llegado a Egipto con la inten- 
ción de adquirir por cuenta del Museo del Louvre algunos manuscritos coptos (Dawson; Huphill, 1995: 275-277). Mariette se interesó por las antigüedades faraónicas y decidió permanecer en Egipto y dedicarse al estudio del Egipto faraónico. En 1857 comenzó a excavar para el jedive Said que quería reunir una colección para regalársela al príncipe francés Napoleón (1808-1873), ${ }^{7}$ que planeaba visitar Egipto; el jedive Said no podía ser menos generoso con Francia de lo que había sido con Austria en 1855. Así Mariette se vio provisto de un barco y de un grupo de hombres a su disposición además de los permisos requeridos para excavar libremente en Saqqara, Giza, Abidos, Tebas y Elefantina.

Un año más tarde Mariette fue nombrado Director de los Monumentos Históricos de Egipto y Director de su Museo. El control de los trabajos arqueológicos estaba en su mano y Mariette inició excavaciones en diversos puntos de Egipto destinadas a liberar los grandes monumentos faraónicos de las arenas del desierto que en algunos casos prácticamente los cubrían, y a desescombrar y eliminar el caserío en aquellos que habían sido ocupados por gentes sencillas que los habitaban con sus animales, aperos y enseres. Estas excavaciones, en las que se empleaba una gran cantidad de mano de obra y en las que el rigor científico prácticamente no existía, sacaban a la luz muchas antigüedades con las que la colección del museo volvió a iniciarse y a crecer rápidamente.

Mariette promovió la obtención de una sede para el Museo de arte faraónico que reuniera las condiciones y requisitos de la museología del momento. Se ocupó para ese fin una casa en Bulaq, entonces un barrio periférico de El Cairo, ${ }^{8}$ próximo al Nilo para facilitar la llegada de las antigüedades, casi siempre de mucho peso y trasladadas en barco. Mariette instaló las oficinas del museo en unas dependencias anejas cedidas por una compañía de transportes fluviales que la expansión del ferrocarril había dejado inactiva. Inicialmente Mariette había pensado como mejor emplazamiento para el Museo de arte faraónico la ciudad de Alejandría, muy visitada por todos los extranjeros que se desplazaban hacia La India y el lejano Oriente; pero cambió Alejandría por El Cairo cuando se comprobó que la línea de ferrocarril que unía ambas ciudades hacía muy fácil y rápida la llegada a la capital del país, idónea para ser sede del museo. Se pensó entonces crear nuevas instalaciones en Ezbekeiya dado que en la zona se ubicaban hoteles elegantes, entre los que destacaba el Shepheard, siempre concurridos por extranjeros. El jedive Ismail (1863-1879) estaba entusiasmado con el proyecto y deseaba que no se limitara a un museo. Su idea se acercaba más a un centro de estudios que habría de contar con un gran museo para antigüedades griegas, islámicas y faraónicas y que habría de estar asociado al Instituto Egipcio, institución francesa de gran prestigio fundada en Alejandría en 1859. Los planes del jedive contemplaban la dotación de un puesto de director con dedicación exclusiva, y la formación de una biblioteca de cuya gestión se ocuparía un bibliotecario. Se pensaba, en definitiva, en la creación del mejor centro científico para estudios del antiguo Egipto (Reid, 2002: 104).

Entretanto Mariette remodelaba y acondicionaba las dependencias de Bulaq, trabajos que conllevaron la construcción de nuevos edificios, probablemente los primeros construidos en Egipto en estilo neofaraónico. El Museo de Arte Faraónico en ellos ubicado fue oficialmente inaugurado el 16 de octubre 1863. Se esperaba que fuera visitado por viajeros extranjeros, cada vez más frecuentes en Egipto, pero también por egipcios, según demuestran varios escritos de Mariette en los que quiere justificar sus criterios expositivos (Reid, 2002: 106-107).

En este ambiente se realizó, en 1864, el viaje a Egipto del español don Antonio Bernal, que se detuvo en el país del Nilo de camino a su destino diplomático en Siria y Líbano. En 1876 Antonio Bernal publicó en Madrid Viaje a Oriente en dos volúmenes, dedicando el primero de ellos a Egipto. Se trata de un relato costumbrista y lleno de detalles que incluye, por supuesto, la descripción de las grandes pirámides de Giza, y el relato de su visita a estos colosales monumentos.

Muy poco después, en 1866, pasó por Egipto, camino de Constantinopla el también diplomático Don Adolfo de Mentaberry que publica sus recuerdos en Madrid en 1873, en el libro titulado Viaje a Oriente. De Madrid a Constantinopla, con un amplio prólogo de Don Antonio Cánovas del Castillo (1828-1897).

\section{8.- Primeras miradas de la investi- GACIÓN ESPAÑOLA HACIA EGIPTO}

En 1867 se creó en Madrid el Museo
7 Primo del emperador Napoleón III (1852-1870).

$8 \mathrm{El}$ inmueble no estaba lejos del actual Ministerio egipcio de Asuntos Exteriores y del edificio de la televisión egipcia. 
Arqueológico Nacional mediante Real Decreto de Isabel II (1830-1904), fechado el 20 de marzo. En la nueva institución debían depositarse las colecciones numismáticas, arqueológicas, etnográficas y de artes decorativas que habían sido reunidas por los monarcas españoles de las Casas de Austria y Borbón, objetos hasta entonces distribuidos entre la Real Biblioteca, el Gabinete de Historia Natural y la Escuela Superior de Diplomática. Con la creación del nuevo museo se decidió construir un nuevo edificio, el Palacio de Bibliotecas, Archivos y Museos que hoy es sede de la Biblioteca Nacional y del Museo Arqueológico Nacional. Mientras se procedía a la construcción del gran inmueble, que no fue concluida hasta 1895, el Museo Arqueológico se ubicó en el llamado Casino de la Reina, antigua finca de la calle Embajadores que había sido regalada en 1816 por el Ayuntamiento de Madrid a la reina Isabel de Braganza, esposa de Fernando VII (1808-1833). En pocos meses, bajo la coordinación del director del nuevo museo, D. Pedro Felipe Montlau y Roca, una buena cantidad de fondos de la nueva institución fue reunida en el Casino de la Reina.

La Arqueología estaba presente en el ambiente intelectual de España en aquel período, y el interés por el antiguo Egipto y por viajar a ese destino eran notables. Como dato de interés podemos recordar que en 1868 , pocos meses después del nacimiento oficial y administrativo del Museo Arqueológico Nacional, el académico Don Antonio Balbín de Unquera leyó, ante la Academia Real Española de Arqueología y Geografía del Príncipe Alfonso, el discurso inaugural del año académico titulado "Arqueología Egipcia" (Balbín de Unquera: 1868: passim; López Grande, 1997: 721-728).

Atendiendo al interés que hacia el antiguo Egipto y la arqueología egipcia se percibía en el ámbito intelectual español y pensando en la necesidad de enriquecer la colección de arqueología nacional y su museo, el director general de Instrucción Pública propuso en un escrito de fecha 26 de agosto de 1869, que facultativos del Museo Arqueológico Nacional viajaran a Egipto acompañando a la misión diplomática que asistiría a la apertura del canal de Suez, para que pudieran visitar lugares de interés arqueológico y adquirir piezas para el museo que serían trasladadas hasta España por buques de la Armada. A pesar de las gestiones realizadas para llevar ade- lante este proyecto, que refleja el interés por una arqueología abierta a las culturas del Mediterráneo, en la inauguración del canal de Suez, celebrada el 11 de diciembre de 1869, estuvo presente la comisión diplomática española, pero sin que en ella participaran facultativos del museo. Sí estaba en dicha comisión el alcalde de Madrid, don Manuel María Galdo, que aprovechó su visita a la tierra de los faraones para adquirir objetos antiguos que a su vuelta fueron donados al Museo Arqueológico Nacional (López Grande, 2004a: 84-86).

En esta misma línea de intenciones se promovió y llevó a cabo el viaje de la Fragata Arapiles al Oriente Mediterráneo. Esta embarcación partió de Nápoles, en el verano de 1871, rumbo a Oriente, llevando a bordo una Comisión Científica dirigida por Don Juan de Dios de la Rada y Delgado, arqueólogo y conservador del antiguo departamento de Prehistoria y Edad Antigua del Museo Arqueológico Nacional. La misión de esta expedición era adquirir antigüedades de los ámbitos mediterráneo, próximo oriental y egipcio, para acrecentar con ellas las colecciones del museo. Pero los contratiempos del viaje fueron muchos, causados, en buena medida, por el exiguo presupuesto del que se disponía, insuficiente para cumplir los objetivos previstos. En su recorrido por los puertos mediterráneos la embarcación permaneció dos días en Alejandría, en donde los científicos pudieron adquirir la cabeza de una estatua masculina de época ptolemaica que hoy se exhibe en el Museo Arqueológico Nacional.

España vivía en aquellos días momentos políticos y económicos muy delicados, situación que sin duda incidió en el escaso éxito de acciones tan interesantes como la promovida en 1869 por Ruiz Aguilera, desde la Dirección General de Instrucción Pública, o el viaje de la Fragata Arapiles, empresas que manifestaban el interés por la arqueología abierta al Mediterráneo, Oriente y Egipto, y por el estudio de los logros culturales y estéticos de las sociedades antiguas de aquellos lugares.

Esa inquietud queda claramente manifestada en la actividad realizada por tres pensionados en la Academia Española de Bellas Artes de Roma, los arquitectos D. Ramiro Amador de los Ríos, D. Anibal Álvarez y el pintor paisista D. Jaime Morera y Galicia, que en la primavera de 1875, una vez finalizadas sus actividades lectivas
9 Ministerio de Asuntos Exteriores (en lo sucesivo MAE), Leg. 4.339, $\mathrm{n}^{\mathrm{O}}$ 32. Comunicado del Director de la Academia Española de Bellas Artes en Roma al Ministro
Plenipotenciario de S.M. D. Diego de Coello y Quesada, fechada en Roma, el 4 de abril de 1875. 
emprendieron, con la aprobación de su director, D. José Casado, "una expedición al Egipto y a la Grecia, donde permanecerán el tiempo que las condiciones del clima permitan en la estación presente, dedicándose a estudios utilísimos que acaso les sirvan de base para sus últimos envíos, y que indudablemente les serán causa de fecunda enseñanza artística". ${ }^{9}$

El seguimiento de la actividad de estos pensionados nos permite conocer que en septiembre de 1876: “...los arquitectos Sres. Amador y Álvarez siguen utilizando su residencia en Grecia, haciendo estudios de detalles y ensayos de restauración sobre aquellos monumentos eternamente hermosos y tratan de aprovechar la inmediata estación para un viaje á Egipto antes de volver a Roma a completar su trabajo de envío...". ${ }^{10}$

Desde Roma, el 12 de diciembre de 1876, el Director de la Academia de Bellas Artes informa al Ministro Plenipotenciario: "Al dar cuenta a V.E. del estado de los trabajos de esta Academia, tengo la honra de poner en su conocimiento que de los señores pensionados que están fuera de Roma tengo noticias satisfactorias (...) El Sr. Álvarez, después de estudiar el Museo de El Cairo ha vuelto á Roma pasando inmediatamente a París á fin de completar la restauración del templo de Apolo que en Grecia había estudiado (...) En tanto que el Sr. Amador ha continuado su expedición al Alto Egipto para estudiar en el templo de Luxor los espléndidos orígenes del arte griego: primer arquitecto español que explora aquellas regiones y aquellos monumentos entre dificultades y privaciones extraordinarias, merece alto aplauso la entereza y el entusiasmo por el arte que tal resolución supone".

Esta información es relevante a la hora de establecer los primeros pasos dados por estudiosos españoles interesados en el arte y la arqueología del antiguo Egipto en las tierras del Nilo. No hablamos ya de viajeros fascinados por Egipto y Oriente, sino de estudiosos de Bellas Artes que emplean su tiempo y los escasos recursos de su pensión para trasladarse a El Cairo y el Alto Egipto, animados por el deseo de estudiar los logros artísticos del Egipto faraónico. La estancia en Egipto de Anibal Álvarez y de Ramiro Amador de los Ríos, ocurre en momen-

10 MAE. Leg. 4.339, $\mathrm{n}^{\mathrm{o}}$ 48, Comunicado de D. José Casado, fechado en Roma 10 de septiembre de 1876.

11 MAE, Leg. 4339, n $^{\circ} 662$.

$12 \mathrm{El}$ museo permaneció en las dependencias de Bulaq hasta la década de 1890. Aquel emplazamiento tenía graves problemas de humedad y en 1878 fue anegado por la crecida del Nilo. La colección fue traslada doce años más tarde a un palacete de del jedive Ismail ubica- tos muy tempranos de la Egiptología. El Museo de El Cairo estudiado por Anibal Âlvarez era el ubicado en Bulaq, dirigido por Auguste Mariette, pues la realidad económica de Egipto, endeudado cada vez más con las naciones europeas, conllevó que el proyecto del centro de estudios del antiguo Egipto que tanto gustaba al jedive Ismail no llegara nunca a realizarse $;{ }^{12}$ la esfinge de Gizeh estaba liberada de las arenas del desierto según se percibe en fotografías realizadas en esas fechas, pero el templo de Luxor, cuya arquitectura interesaba a Ramiro Amador de los Ríos para un proyecto de estudio definido, conocer "los espléndidos orígenes egipcios del arte griego", permanecía aún cubierto de ruinas, arena y escombros, pues sabemos que el Servicio de Antigüedades Egipcio se ocupó de su limpieza una década más tarde.

De 1873, sólo tres años antes de la visita de D. Ramiro Amador de los Ríos, tenemos la descripción de su visita al templo de Luxor que la británica Amelia B. Edward (1831-1892; Rees, 2000), nos dejó en su afamado libro $A$ Thousand Miles up de Nile, publicado en Londres en 1877:

"Luxor es un pueblo grande habitado por una mezcla de árabes y coptos (...) el templo ha formado el núcleo de la ciudad, cuya parte más antigua ha crecido dentro y alrededor de las ruinas. La entrada principal mira al norte hacia Karnak. Las torres gemelas del pilono, deterioradas, con las cornisas caídas, y aprisionadas en escombros, son aún grandiosas. En el frente, y a cada lado de la puerta central, hay sentados dos colosos con corona, maltratados, sin cara y enterrados hasta la barbilla (...). A pocas yardas frente a ellos, se levanta un obelisco solitario, también medio enterrado. Los colosos son de granito negro; el obelisco es de granito rojo (...). Su compañero, ya deteriorándose imperceptiblemente bajo las influencias de un clima extraño, observa con indiferencia las pequeñas revoluciones y contrarrevoluciones de la Plaza de la Concorde (...). Tras esta entrada se extiende un intrincado laberinto de callejones y pasadizos ahumados y sucios. Chozas de adobe, palomares de adobe y una mezquita de adobe, están pegados como avisperos dentro y alrededor de las ruinas. Arquitrabes labrados con los títulos reales serví-

do en Giza, un lugar que tampoco era adecuado para la exposición de los objetos faraónicos, pero que los acogió hasta que en 1902 se concluyera e inaugurara el actual museo Egipcio de El Cairo, el hermoso edificio de inspiración grecorromana, de amplias dimensiones, dotado de biblioteca y espaciosos jardines proyectado por el francés Marcel Lazare Dourgon (1858-1911) construido en la capital egipcia. 
an de apoyo a los tejados de escuálidas cabañas. Exquisitos capiteles asomaban por entre cobertizos en los que los búfalos, camellos, burros, perros y humanos convivían en insalubre hermandad. Los gallos cantaban, las gallinas cacareaban, las palomas se arrullaban, los pavos emitían su sonido característico, los niños enredaban, las mujeres cocían el pan y parloteaban, y toda esa rutina sórdida de la vida árabe tenía lugar entre caminos tortuosos que enmascaraban las columnatas y borraban las inscripciones de los faraones. Seguir el plano de esta parte del edificio era entonces imposible ..." (A.B. Edwards, ed. 2003: 123-126).

Como el Director de la Academia de Bellas Artes de Roma, D. José Casado, indicara en sus informes, los investigadores españoles que visitaron Egipto en aquellas fechas, muy especialmente D. Ramiro Amador de los Ríos, merecen un gran reconocimiento, máxime cuando conocemos por la misma fuente que llevar a cabo su empresa no hubo de ser sencillo, dadas las privaciones derivadas de la exigua pensión que la Academia ofrecía a sus pensionados, y la realidad de Egipto en aquellos días.

En marzo de 1877 D. José Casado informa al Ministro Plenipotenciario: "Participaré a V.E. la inquietud en que estoy por la falta de noticias del Sr. Amador de los Ríos deseando atribuir este hecho a la dificultad de comunicaciones con el Alto Egipto, y que me he dirigido telegráficamente al cónsul de España en El Cairo en averiguación de las que pueda tener de este animoso artista que se ha empeñado en exploraciones aventuradas impulsado por el noble afán del estudio". ${ }^{13}$

No conocemos por ahora más datos acerca de la aventura de Ramiro Amador de los Ríos en Egipto, pero sabemos que volvió de la tierra del Nilo con su investigación realizada, que fue presentada como trabajo de segundo año de estancia en la Academia de Bellas Artes de Roma. Prosiguió después con estudios de arquitectura clásica, pues su obra de tercer año en la Academia de Roma fue un estudio del templo de Antonino y Faustina, en el foro romano, que obtuvo muy alta calificación (M. Bru Romo, 1971: 139).

Por aquellos años Egipto seguía atrayendo a la alta burguesía española. Algunos viajes, realizados por placer o motivos de trabajo, conllevaban la formación de colecciones de antigüedades, casi siempre pequeños objetos, que en oca- siones fueron vendidas o donadas al Museo Arqueológico Nacional que fue incrementando así su colección egipcia (E. Pons Mellado, 2001: 295-307). Las colecciones más significativas fueron la de D. Tomás Asensi, comprada por el Museo en 1876; la de D. Víctor Abargues, adquirida por el Museo en 1877 y la de D. Eduard Toda i Güell, cónsul español en El Cairo entre 1884-1886, que llegó a formar una abundante e interesante colección de antigüedades egicias, hoy repartidas entre la Biblioteca-Museo Víctor Balaguer de Vilanova i la Geltrú (Barcelona) y el Museo Arqueológico Nacional de Madrid. Desde su llegada a Egipto Eduard Toda i Güell estuvo en contacto con Gaston Maspero, sucesor de Auguste Mariette en el Sevicio de Conservación de Antigüedades de Egipto. Toda i Güell se interesó por el conocimiento y estudio del antiguo Egipto y Nubia. Amigo de Maspero, frecuentaba el círculo de egiptólogos que residían en aquellos años en El Cairo y en Luxor. En enero de 1886 Eduard Toda tomó parte en la expedición al Alto Egipto que todos los años emprendía el Servicio de Conservación de Antigüedades de Egipto, que recorrió las ruinas de Menfis, Saqqara, Asiut y Dendera, deteniéndose algunos días en Tebas, donde Toda llegó a verse involucrado en importantes trabajos arqueológicos, como la excavación de la tumba del noble Sennedyem, en Deir el Medina (Montero Blanco, 1990: 20), realizada bajo su supervisión en enero de 1886, mientras Maspero se ocupaba del desescombro del enorme templo de Luxor, abrumadora tarea que la escritora Amelia Edwards recordó en la edición de su libro A Thousand Miles up the Nile de 1891:

"El profesor Maspero durante los dos últimos años de su cargo oficial (...) ha hecho por esta grandiosa reliquia de la época faraónica lo que su predecesor (Auguste Mariette) hizo por el más reciente templo de Edfú. Las dificultades de realización de esta gran empresa fueron tan desmesuradas que al principio parecieron insuperables. Primeramente los felahin rehusaron vender sus casas; Mustafá Aga pidió el exorbitante precio de 3.000 libras por su residencia consular, construida entre las columnas de Horemheb, mirando al río; y no se pudo conseguir el permiso para derribar la mezquita del primer gran patio del templo a ningún precio. Tras doce meses de negociaciones, los felahin fueron expropiados a un precio justo (...) Alrededor de treinta familias aceptaron abandonar el lugar, aunque ocho o diez se resistían a marcharse a ningún precio. Los trabajos de 
demolición comenzaron en 1885. En 1886, las pocas familias que se aferraban al lugar, siguieron el ejemplo de las otras; y en el transcurso de la temporada se limpió el templo de lado a lado, quedando tan solo la antigua mezquita dentro del recinto, así como la casa de Mustafá Aga en el lateral del río. Siguió la dimisión del profesor Maspero en 1887, y desde entonces los trabajos fueron supervisados por su sucesor, M. Grébaut, consiguiendo que, en lugar de un sórdido laberinto abarrotado de chozas de adobe, patios, establos, pasadizos y montones de basura, apareciera un noble templo, sólo superado por el de Karnak, de grandioso diseño y belleza de proporciones, que ahora ostenta sus avenidas de columnas y realza sus arquitrabes labrados que surgen a lo largo de la orilla del Nilo" (A. Edwards, ed. 2003: 128).

Toda i Güell siguió, sin duda, de cerca estos avances de la Egiptología. Su interés en la disciplina le llevó a crear los llamados "Estudios Egiptológicos", serie de publicaciones que recogió hasta tres monografías del citado autor. La intención de Toda i Güell era crear en España una escuela egiptológica, pero aquella iniciativa no pasó de ser un interesante propósito que lamentablemente no llegó a cristalizar.

El interés por el antiguo Egipto quedó también plasmado en la producción científica de otros estudiosos españoles cuyas obras vieron la luz antes de alcanzar el siglo XX, como ya hemos comentado en trabajos previos (López Grande, 1997: 721-723; 2004: 88-89). La Egiptología apasionaba en España como en otros lugares de Europa y en América. Durante el siglo XIX la Egiptología vivió en nuestro país una fase inicial en la que destaca el esfuerzo individualizado de algunas, muy pocas, personas y en la que las instituciones apenas participaron. Los logros de esta primera etapa, en la que se dieron los primeros pasos, fueron escasos. Sin embargo, aquellos primeros pasos y aquellos primeros logros fueron suficientes y significativos para mantener viva en nuestro país la inquietud por la Egiptología que no ha cesado y que avanza con firmeza (López Grande, 2000: passim; 2004: 89-101).

\section{Bibliografía}

ASSMANN, J. (2003): Moisés el egipcio. Madrid.

BRIER, B (1996): Momias de Egipto. Las claves de un arte antiguo y secreto. Barcelona

BRU ROMO, M. (1971): La academia española de bellas Artes en Roma (1873-1914). ministerio de Asuntos Exteriores.
Dirección General de Relaciones Culturales. Madrid.

BALBÍN DE UNQUERA, A. (1868): Arqueología egipcia. Discursos leídos ante la Academia Real Española de Arqueología y Geografía del Príncipe Alfonso en el acto solemne de la inauguración del año académico 1868. Madrid.

BENSON, A.CH. (1917): Life and Letters of Maggie Benson. Londres.

CANNUYER, CH. (1991): "Visions d'Égypte: continuité et ruptures du Moyen Age aux débuts de l'égyptologie " Chronique d'Égypte (CdÉ) 66 (1991), 136-147.

CANNUYER, CH. (1998): "La description des pyramides par Diego de Mérida (1510)" en SIRUN-GRUMACH (ed.) Jerusalem Studies in Egyptologie (Ägypten und Altes Testament. Studien zu Geschichte, Kultur und Religion Ägyptens und des Altes Testament, 40) Wiesbaden, 9-18.

CLAYTON (1984): The Rediscovery of Ancient Egypt. Artist and Travellers in the $19^{\text {th }}$ Century. Londres.

DAWSON, W.R.; UPHILL, E.P.A. (1995): Who was who in Egyptology. (3a. Edición revisada por BIERBRIER, M.). Londres.

DANNENFELDT, K.H. (1959): "Egypt and Egyptian Antiquities in the Renaissance" Studies in the Renaissance 6 (1959) 7-27.

DOURSTHER, H. (1945): Dictionnaire Universel des poids et mesures anciens et modernes. Amsterdam.

EDWARD, A.B. (ed. 2003): Mil millas Nilo arriba. (Traducción y prólogo de R. Pujol). Barcelona.

GALÁN, J.M. (1997): "El viaje de Unamón y la embajada de los Reyes Católicos a Egipto" Congreso Español de Antiguo Oriente Próximo. El Mediterráneo en la antigüedad: Oriente y Occidente. (Madrid, 29 sept. 2 octubre, 1997), Madrid 8-18.

GUÉRIN DALLE MESE, J. (1991): Égypte, la mémoire et le reve. Itinéraires d'un voyage, 1320 (Bibliotheca dell' Archivum Romanticum, Série I, vol. 237) Florencia.

GIL PALENQUE, C. (2001): El impacto de los descubrimientos egipcios en las corrientes de pensamiento del siglo XIX” en J.M. CÓRDOBA ZOILO, R. JIMÉNEZ ZAMUDIO Y C. SEVILLA CUEVA (edit): El Redescubrimiento de Oriente Próximo y Egipto. Viajes, hallazgos e investigaciones. (Supplementa ad Isimu. Estudios Interdisciplinares sobre Oriente Antiguo y Egipto II Series: Acta et Symposia, Vol. I). 337-345. Madrid.

GÓMEZ ESPELOSÍN, F.J.; PÉREZ LARGACHA, A. (1997): Egiptomanía. El mito de Egipto de los griegos a nosotros. Madrid.

GÓMEZ.NAVARRO, J. (2002): “Viajeros españoles en 
Egipto.” Sociedad Geográfica Española, 13, 98-123. Madrid.

KURZ, M.; LINANT DE BELLEFONDS, P. (1998) : « Linant de Bellefonds : Travels in Egypt, Sudan and Arabia Petraea, 1818-1828 » en SARKEY, P ; STARKEY, J. (edit): Travellers in Egypt. Londres Nueva York, 61-70.

LÓPEZ GRANDE, M.J. (1997): "Los estudios de Egiptología en España y la Asociación Española de Egiptología” en MORA, G.; DÍAZ-ANDREU, M. (edit): La cristalización del pasado: Génesis y desarrollo del marco institucional de la arqueología en España. Málaga, 721-728.

LÓPEZ GRANDE, M.J. (2000): "La arqueología española en Egipto y Sudán: Historia de una labor reciente” III Congreso de Arqueología Peninsular. Vol. I: Arqueología Peninsular. História, teoria e práctica. 431440. Porto.

LÓPEZ GRANDE, M.J. (2001): “Configuración y exhibición de la colección de antigüedades egipcias del Museo Británico. Los primeros años: 1756-1924” en J.M. CÓRDOBA ZOILO, R. JIMÉNEZ ZAMUDIO Y C. SEVILLA CUEVA (edit): $E l$ Redescubrimiento de Oriente Próximo y Egipto. Viajes, hallazgos e investigaciones. (Supplementa ad Isimu. Estudios Interdisciplinares sobre Oriente Antiguo y Egipto II Series: Acta et Symposia, Vol. I). 277-294. Madrid.

LÓPEZ GRANDE, M.J. (2002): “Aventureros, sabios y arqueólogos a la orilla del Nilo. El redescubrimiento del antiguo Egipto” Sociedad Geográfica Española, 13, 64-83. Madrid.

LÓPEZ GRANDE, M.J. (2004a): "Viajeros y arqueólogos españoles en las tierras del Nilo. Historia de una aventura en curso" en M. ALGABA y J.L. ARSUAGA (edit): Expediciones arqueológicas y excavaciones antropológicas: Viajeros españoles tras los pasos de las civilizaciones perdidas, 79-102. Madrid.

LÓPEZ GRANDE, M.J. (2004b): "Relatos y estampas de los viajeros del siglo XIX. David Roberts: sus viajes, grabados y acuarelas" Platea 11, 14-17. Madrid.

LUCAS PELLICER, M.R. (2002): "Experiencia española en la Campaña de la UNESCO para el salvamento de los restos arqueológicos de Nubia" en M.J. LÓPEZ GRANDE (edit): Culturas del Valle del Nilo. Su historia, relaciones externas e investigación española. 189-204. Barcelona.

MONTERO BLANCO, T. (1990): Eduard Toda. Antic Egipte. Documentacio Manuscrita. Barclona.

NIGHTINGALE, F. (1998): Letters from Egypt. A Journey on the Nile 1849-1850. Londres.

PONS MELLADO, E. (2001): "El redescubrimiento de Egipto por españoles: las primeras colecciones del Museo Arqueológico Nacional" en J.M. CÓRDOBA ZOILO, R. JIMÉNEZ ZAMUDIO Y C. SEVILLA CUEVA (edit): El Redescubrimiento de Oriente Próximo y Egipto. Viajes, hallazgos e investigaciones. (Supplementa ad Isimu. Estudios Interdisciplinares sobre Oriente Antiguo y Egipto II Series: Acta et Symposia, Vol. I). 295-308. Madrid.

REID, D.M. (2002): Whose Pharaophs? Archaeology, Museums, and Egyptian National Identity from Napoleon to World War I. The American University in Cairo Press. Cairo.

RODRÍGUEZ-MOÑINO, A. (1946): Viaje a Oriente. (Analaecta Sacra Taraconensia, 1).

ROMER, J. (1985): Los últimos secretos del Valle de los Reyes. Una singular aventura arqueológica. Barcelona.

REES, J. (2000): Amelia Edwards. Traveller, Novelist E Egiptologist. Londres.

REEVES, N; WILKINSON, R.H. (1999): Todo sobre el Valle de los Reyes. Tumbas y tesoros de los principales faraones de Egipto. Barcelona.

ROMER, J. (1985): Los últimos secretos del Valle de los Reyes. Una singular aventura arqueológica. Barcelona.

SANTOS OTERO, AURELIO (1991): Los evangelios apócrifos. Colección de textos griegos y latinos. Versión crítica, estudios introductorios y comentarios. Biblioteca de Autores Cristianos. Madrid.

TAFUR, P. (1874): Andanças é viajes. Madrid, 1874.

WORTHAM, J.D. (1971): British Egyptology 1549-1906. Oklahoma. 